\title{
FÍSICA DO MEIO AMBIENTE: ESTADO DA ARTE.
}

\section{Thiago Moura Zetti1; Milton Souza Ribeiro Miltão².}

1. Bolsista PROBIC/CNPq, Graduando em Licenciatura em Física, Universidade Estadual de Feira de Santana, email: zetti.tm@gmail.com

2. Orientador, Departamento de Física, Universidade Estadual de Feira de Santana, e-mail: miltaaao@gmail.com

PALAVRAS-CHAVE: Física; Teoria e Leis gerais; Questão Ambiental

\section{INTRODUÇÃO}

Os problemas socioambientais como ameaçadores a sobrevivência da vida na terra é um fenômeno relativamente novo para a humanidade. A medida que a humanidade foi se desenvolvendo industrial e tecnologicamente, e assim, se distanciando da natureza, ela passou a vê-la de forma fragmentada, como uma fonte de recursos que poderiam ser transformadas em bens consumíveis, deixando de encara-la como parte de um todo em equilíbrio. Com essa mudança de visão, logo, consequências com o passar do tempo foram surgindo, mostrando que esse tipo de visão não era sustentável: primeiro, os recursos provenientes da natureza são finitos e insuficientes para alimentar toda a demanda crescente da sociedade de consumo, e em segundo, uma pequena parcela da população desfruta do bem estar e ilusório do consumo, enquanto a grande maioria da população luta apenas para sobreviver, e são os que sofrem com os graves problemas ambientais gerados pelo próprio modelo econômico.

A questão ambiental é um dos assuntos mais polêmicos e atuais que deve ser bastante debatido e criticado. Para que esses debates e discussões acerca da questão ambiental ocorra, é necessário ter conhecimento sobre o assunto, e uma ferramenta fundamental para suprir essa necessidade é a Educação Ambiental.

Para Fien (1988), a Educação Ambiental é uma abordagem curricular de aprendizagem necessária para que indivíduos e grupos compreendam o meio ambiente com o objetivo final de desenvolver atitudes de cuidado e comprometimento, potencializando o desejo de agir de forma mais responsável no meio ambiente.

A Educação Ambiental tem como objetivos: promover a consciência clara e interesse sobre interdependência econômica, social, política e ecológica em áreas urbanas e rurais; proporcionar a cada pessoa a oportunidade de adquirir os conhecimentos, valores, atitudes, compromisso e habilidades necessárias para proteger e melhorar o ambiente; criar novos padrões de comportamento de indivíduos, grupos e sociedade como um todo em relação ao ambiente (FIEN e TILBURY, 1996).

A abordagem da Educação Ambiental geralmente ocorre de três formas (FIEN e TILBURY, 1996; HUCKLE, 1993; Le GRANGE, 2002): educação sobre o ambiente (que está ligada a educação para a gestão ambiental e controle, enfatizando o conhecimento sobre os sistemas e processos naturais), educação no/através do ambiente (onde o seu foco é 'educação para a consciência ambiental', enfatizando a experiência dos estudantes no ambiente, para desenvolver capacidades de clarificação de valores e competência), e educação para o ambiente ('educação para a sustentabilidade', que tem como foco a crítica da educação de valores, mudança e transformação social através da ação baseada na exploração e o envolvimento na resolução de problemas ambientais). 
Há uma necessidade de valorizar e disseminar praticas educativas que envolva a pratica da Educação Ambiental, desse modo, vemos a importância do papel da escola tanto na divulgação e discussão dos processos científicos quanto no desenvolvimento da capacidade de compreensão, avaliação, utilização e julgamento pelo aluno, do conhecimento. Para Loureiro (2006), o processo educativo é fundamental para o desenvolvimento intelectual humano. Ressaltamos a importância do professor no âmbito escolar que deve buscar a clarificação dos valores e atitudes dos alunos no modo como percebem e avaliam os fatos ou eventos estudados, aproveitando assim para introduzir a educação ambiental no processo ensino-aprendizagem.

\section{MATERIAL E MÉTODOS}

A primeira etapa do projeto foi dedicada a um programa de estudo no qual o bolsista fez uso do referencial teórico para uma melhor compreensão das questões filosóficas do conhecimento humano, da Educação Ambiental e da relação entre Ciência e Tecnologia.

Em uma segunda etapa foi dedicado ao estudo das teorias e leis gerais visando compreender suas relações com aspectos socioambientais.

\section{RESULTADOS E DISCUSSÃO}

As mudanças globais de comportamento e a relação ser humano/meio ambiente impõem diversas adequações em todos os setores da sociedade, e o ensino de física devido a sua relevância necessita ajustar à sua maneira de apresentar e contextualizar os conceitos físicos de maneira que estudantes (no contexto escolar) ou um público em geral (no contexto de atividades em uma comunidade, como a SIRIBEIRA) sintam-se mais instigados a conhecer mais sobre os fenômenos da natureza.

Atualmente, no Brasil, as problemáticas ambientais, citando como exemplo as metas estabelecidas de aceleração do crescimento econômico, que tem voltado as atenções para o desafio da geração de energia, e é o centro de intensos debates ambientais, merece que nas discussões sobre a temática da geração de energia, receba um enfoque ambiental e não apenas sob o ponto de vista físico da questão. Tratar de assuntos como esse em sala de aula ou em outros ambientes é dar argumentos e base de conhecimento para que o público em geral, consiga se expressar no momento de avaliações desse tipo.

Numa perspectiva filosófica, a questão socioambiental pode ser compreendida como uma relação das "formas de apropriação do mundo e da natureza pelos seres humanos, por meio das relações de poder que foram inscritas nas formas dominantes da ação humana" (LEFF, 2002, p.17), não deixando de considerar o fato de que "a nossa empatia instintiva com os ambientes terrenos permanece atrofiada em pessoas mais contemporâneas" (ABRAM, 2010, p.42). A questão socioambiental apresenta problemas epistemológicos e ontológicos. Epistemológicos, porque sendo o conhecimento tão vasto e amplo, em que configuração e através de quais configurações os seres humanos irão estabelecer sua relação de poder com as formas de apropriação do mundo e a natureza? Ontológico, porque sendo parte do universo, em que essência, em 
que qualidade, os seres humanos constituem suas formas de apropriação do mundo e da natureza?

Para uma compreensão e racionalidade socioambiental mais profunda, a partir desses problemas, se torna necessário um ponto de vista filosófico diferente, onde se tenha um diálogo entre diferentes campos do saber e uma visão sistêmica que os compõem (perspectiva transdisciplinar) considerando uma visão de conhecimento que seja cosmológica (que leve em conta as dimensões espaciais e temporais do universo), holística (que defende a importância de uma compreensão integral dos fenômenos, em vez de uma análise isolada de seus componentes), histórica (porque leva em conta os fatos que antecederam o conhecimento atual), construtivista e dialógica já que o problema socioambiental se reflete em todos os fenômenos, pelas suas diferentes nuances. Com isso, estamos levando em conta que as origens da questão ambiental são filosóficas (LEOPOLD, 1986).

\section{CONSIDERAÇÕES FINAIS}

Com o estudo do referencial teórico sobre Educação Ambiental ficou evidente que é preciso utilizarmos ela como ferramenta para tratarmos da questão ambiental, é necessário que a sociedade tenha conhecimento sobre essa questão para que possa participar de debates e discussões, e que possa analisar, refletir criticamente sobre o que será melhor para o meio ambiente, visto que, estamos inseridos nele; precisamos voltar a vê-lo como um todo em equilíbrio. Com essa compreensão, é possível reverter as problemáticas ambientais que nos assolam atualmente. De acordo com Rothschild (2007), a humanidade tem real condições de impedir a continuidade desse problema, sem se intimidar com o seu tamanho. Se cada pessoa fizer uma pequena ação positiva, a soma do todo, pode levar a efeitos decisivos. O ser humano é a única espécie que depende do todo para sua sobrevivência neste planeta. É a única que tem esta consciência e o poder de intervir benéfica ou maleficamente no ambiente e, portanto, sua responsabilidade é inigualável.

Com isso, vemos a importância desse trabalho teórico inicial e a necessidade de darmos continuidade com uma possível aplicação. A inclusão da visita à comunidade de Siribinha, distrito da cidade do Conda-BA que não estava prevista no plano de trabalho, foi bastante satisfatório, onde vimos uma série de possíveis áreas de atuação juntamente com a Associação SIRIBEIRA que atua em diversas comunidades da região. Essa inserção da Educação Ambiental juntamente com a Física, é de grande importância para a comunidade em geral, uma vez que, o conhecimento científico é um elemento-chave na cultura geral dos indivíduos (cidadãos e camponeses), pois o acesso a esse conhecimento os habilita para se posicionarem, tanto ativamente diante das modificações do mundo em que vivem, quanto para compreender os fenômenos observáveis na Natureza e no Universo.

\section{REFERÊNCIAS}

MILTÃO, M. S. R. UMA PROPOSTA DE ESTUDO FILOSÓFICO DO SER SOCIAL DO MOVIMENTO AMBIENTAL. 35 $5^{\text {a }}$ Reunião Anual da Associação 
Nacional de Pós-Graduação e Pesquisa em Educação. Porto de Galinhas: ANPEd. 2012. p. 18.

FOGAÇA, Daniela Silva. FÍSICA X MEIO AMBIENTE: A IMPORTÂNCIA DA FÍSICA NOS FENÔMENOS RELACIONADOS AO MEIO AMBIENTE. 2013. 32 f. Monografia (Especialização) - Curso de Especialização em Ensino de Ciências, Universidade Tecnológica Federal do Paraná, Medianeira, 2013.

MILTÃO, M. S. R. Philosophical-Critical Environmental Education: a proposal in a search for a symmetry between subject and object. Journal of Social Sciences (COES\&RJ-JSS), v. 3, p. 323-356, Abril 2014.

RODRIGUES, J. J. V. ENSINO DE FÍSICA E PRESERVAÇÃO AMBIENTAL: A IMPORTÂNCIA DAS SAÍDAS A CAMPO. CADERNO DE FÍSICA DA UEFS, Feira de Santana, 15(01), 2017. 1601.1-16. 